\title{
Parents Perspective toward Implementing Pivotal Response Treatment in Natural Environment to Enhance Social Communication and Sensory Processing of Children with Autism
}

\author{
Dr. Mariam Alshirawi, PhD \\ Associate Professor - Intellectual Disability \& Autistic Program \\ Arabian Gulf University, Kingdom of Bahrain
}

Dr. Rehab Alzayer, PhD

Case Supervisor/Counselor

Stepping Stones Center for Autistic Spectrum Disorders, Al Khobar-KSA

Dr. Salman Baqer Alnajjar, MD

Received: May 9, 2018 Accepted: July 10, 2018 Published: August 1, 2018

doi:10.5296/jse.v8i3.13378 URL: https://doi.org/10.5296/jse.v8i3.13378

\begin{abstract}
Parents of children with autism face many challenges while raising such a child due to behavioral, social, and sensory related characteristics. Qualitative focus group methodology was used to examine the effects of providing Pivotal Response Treatment (PRT) intervention in the natural environmental activity of horseback riding on improving social communication, and sensory processing of children with Autism Spectrum Disorder (ASD). The purpose of this qualitative study was to describe parents' perceptions of how this intervention affects the lives of their children at home and across various natural settings. Key influences included (a) eye contact and joint attention, (b) peers and adults' interaction, (c) verbal and non-verbal communication, (d) behavior management, (e) eating and sleeping organized patterns, and (f) self-stimulatory behaviors. These elements were discussed across all parents who participated in the study. However, specific experiences and outcomes varied across the critical influences
\end{abstract}


mentioned above.

Keywords: Autism Spectrum Disorder, horseback riding, Pivotal Response Treatment, Qualitative Method, social communication, sensory processing. 


\section{Introduction}

Autism Spectrum Disorder (ASD) is a developmental disability that adversely affects the verbal and non-verbal communication, sensory regulation, and social interaction capability of an individual. Children diagnosed with ASD poses special characteristics that are a challenge to the caregivers who stay with the children daily (Howlin, 2006). Deficits in social communication, language acquisition, and deficiency in generalizing specific complex social behaviors are core features of Autism Spectrum Disorder (ASD). Social interaction is broadly defined as an individual's ability to respond to social bids and initiate and maintain interactional discourse (Adamson, McArthur, \&Markov, 2001; Bruinsma, Koegel, \&Koegel, 2004; Jones \& Schwartz, 2009). Social communication impairments are typically manifested by the difficulty in responding to verbal initiation exhibited by other factors such as inappropriate facial expressions, lack of eye contact during social interactions, and lack of joint attention skills. Equally important, absence of verbalization and echolalia are additional symptoms of ASD (Koegel et al., 1993; Pierce \& Schreibman, 1995). In addition, many children with Autism Spectrum Disorder (ASD) have difficulties processing everyday sensory information, which is indicated in the autism diagnosis criteria (DSM-5, 2013). Sensory processing difficulties fall under "restricted, repetitive patterns of behaviours" descriptors behaviour. Often, children with autism exhibit hypo or hypersensitivity behaviours in activities such as body movements, visual, tasting auditory, smelling and tactile. Sensory behaviours manifested through seeking or getting rid of any sensory stimulation in a particular environment are other challenges among children with ASD (Ashburner, Ziviani, \& Rodger, 2008). These characteristics affect children from various parts of the world(Dawson, 2008) \& (Mundy, Sigman, \& Kasaire, 1990).

Research has indicated the need to improve social behavior at an early age to provide these individuals with the prerequisite communication skills needed for distinctive child development. (Baker, Koegel, 1998) In addition, one of the common features of autism that influences the social communication of children with autism is social difficulties (Baker et al., 2008; Hilton et al. 2010). Ausderau et al. (2014) reported data from the Sensory Experience Questionnaire conducted on 1200 child with autism aged 2-12 years. Their study revealed that the most common sensory problems were hypo-hyper reactivity, atypical sensory interests, and repetitions. One of the most common sensory dysfunctions in children with autism is sensory adaptive. Sensory adaptive might range from sensitive to extreme problems in taste, smell, touch, and sound. In the study, children with autism exhibited the inability to discriminate and generalize sensory stimuli in addition to sensory seeking and auditory filtering difficulties (Schaaf, \& Lane, 2015; 2014). The authors concluded that there is a relationship between poor auditory filtering and excessive sensory seeking and adaptive social problem primarily with school-age children with autism (Ashburner et al., 2008). Similarly, Hochhauser, \& Engel-Yeger, (2010) found low social engagement during participation in school activities among children with autism who exhibited a pronounced level of sensory sensitivity. The dysfunctional sensory system either over or under-responsive to various sensory input that most of the children with autism experience may be the underlying reasons for many social communication and behavior problems. Some of the maladaptive behaviors 
that might be a result of sensory issues include rocking, spinning, and hand flapping. Besides, over or under responsive sensory dysfunction might affect these children's attention, their ability to attend to tasks, and their potential for social engagement (Ausderau et al., 2014).

Despite the number of studies that examined the relationship between sensory processioning and social communication, further sensory assessment is highly recommended to provide more insight regarding the sensory features associated with social difficulties in children with autism (Schaaf et al., 2015; 2014). One of the widespread intervention that has been applied to enhance children's attention, awareness, and overall arousal associated with sensory problems is the sensory integration technique. The sensory integration technique includes exposing the child to different types of stimuli in their environment. The inter-relationship of the senses through pressure, touch, smell, or sounds supports the child's ability to interpret and respond to different stimuli around them and also facilitate their social engagement in various educational and community settings (Ashburner et al., 2008). However, solely sensory integration techniques continue to lack adequate scientific basis; Thus, it is critical to integrate the sensory integration approach with other strong validated interventions to maximize the social and positive functioning of children with autism (Baranek, 2002; Dawson \& Watling, 2000)

Fortunato, Sigafoos, and Morsillo-Searls (2007) provided an overview of the literature about how the treatment of autism with the use of interventions based on Applied Behavior Analysis (ABA), affects the communication skills of individuals with autism. Pivotal Response Treatment is a type of ABA intervention strategies that have been supported by empirical research to increase the communication skills of children with autism. This intervention has been identified to have a positive impact on other areas that have not been primarily targeted by the technique such as sensory and behavior. Pivotal Response Treatment isrequired to deliver the intervention in a natural environment, using natural reinforcements, and emphasizing the importance of direct and immediate reinforcements (Lovass, 1987; Yoder \& Stone, 2006; Koegel and Koegel, 2006, and Prizant et al., 2008). The long-term outcomes of such intervention include enhancing functional communication skills through utilizing each child's natural motivations so the child could generalize the use of the competencies across different settings and with different people on the natural environment (Coolican, Smith, \& Bryson, 2010).

Underlying PRT is motivational strategies that are used to teach language skills, reduce disruptive or self-stimulatory behaviors, increase social communication skills, and increase academic skills (Koegel et al., 2006). These researchers identified several central behavioral areas that when treated, produce substantial gains in desired outcomes due to the intervention. The behavioral regions include motivation in which the child is willing to engage interactively in social communication activities, social initiation in which child initiates participation in enjoyable activities, and self-regulation in which the child can manage and monitor personal behaviors.

Motivation and self-initiation are the primary pivotal areas of PRT intervention. Initiating social motivation for children with autism is an essential value related to the importance of being engaged in meaningful social interaction. Specific PRT motivational techniques include 
following the child's preferred items, varying task difficulties, rewarding and reinforcing immediately and continually, and delivering natural reinforcement that is related to the child's response (Koegel, Camarate, \& Valdez-Menchaca, 1998). Other pivotal areas include self-management and the ability to respond to multiple cues or prompts. By targeting the pivotal essential areas, individuals with autism will exhibit progress in other areas that are not targeted in the intervention (Koegel et al., 2006).

The most significant aspect of PRT approach is the child-directed approach. In this methodology, the child determines the direction of the therapy by making choices. The toddler determines the activities and objects that will be utilized during the intervention (Koegel et al., 2006). Children with autism often demonstrate a lack of verbal initiation required to prompt language acquisition. Therefore, enhancing their motivation with specific PRT techniques will assist students to initiate meaningful verbal communication and ensure the generalization of oral initiation across different settings, stimuli, or people (Koegel et al., 1998).

Moreover, Generalization and maintenance have been at the heart of the intervention core for children with autism. Therefore, implementing the intervention in a natural environment has given significant attention concerning responses provided by controlling the stimuli in the natural environment (National Research Council, 2001). In addition, motivational components in the PRT intervention package can be better promoted in the natural environment where children have their preferred activities and reinforcements (Koegel et al., 2006). Researchers observed that the natural environment paradigm leads to collateral intervention gains in targeted and non-targeted areas such as academic, behavior, and social developments in addition to the generalized effect across individuals and settings (Baker, Koegel, \&Koegel, 1998; Baker, 2000; Koegel, Koegel\& Surratt, 1992; Koegel, O’Dell \& Dunlap, 1988).

Equally important, Family involvement was an integral part of PRT. The notion of active parent involvement as interventionists could support the efficacy of targeted pivotal areas such as motivation. The active parent involvement provided families with a "goodness of fit intervention" in which the intervention strategies naturally blended within the family sociocultural system (Lucyshyn, Albin, \& Nixon, 1997; thereby, increasing opportunities for student generalization.

One of the therapy approaches that emphasized the role of the natural environment is therapeutic horseback riding. Therapeutic horseback riding is one form of animal-assisted therapy that has been drastically increased during the last forty years (Prothmann \& Fine 2011). Recent developmental research demonstrated that both typically developing children and toddlers with autism show a natural interest towards animals and other non-human aspects in their environments. Therapeutic horseback riding has extended the effect of animal research on social functioning of children with autism in regard of using horseback riding as a treatment to enhance posture, balance, mobility and laterally developing the therapeutic bond between the horse and the child with autism (Martin \& Farnum, 2002). Riding a horse involved many skills such as self-control, attention and focus, sensory integration, and verbal 
or non-verbal communication. It also consisted of multisensory integration, contact with the horse, psychological stimulations, and social responses. Consequently, this type of therapy can benefit children with autism who exhibited deficits in join-attention, social communication, and sensory integration and management (Prothmann et al., 2011).

Ward et al., 2013 conducted a study in 21 children with autism. They utilized a single group quasi-experimental interrupted time series design to examine the associations between therapeutic horseback riding, social communication, and sensory processing in children with autism. All children attended the therapeutic horseback riding for 10 consecutive weeks followed by a 6 weeks break to investigate whether or not the children were able to maintain the therapeutic effect following the withdrawal of the therapeutic riding effects. The teachers of this study conducted pre and post of two measures. The measures included the Gilliam Autism Rating Scale: Second Edition (GARS-2) that was used to assess autism characteristics, and the Sensory Profile School Companion (SPSC) that was utilized to measure the children's sensory processing abilities. The results indicated that all children showed improvement in their social communication, tolerance, and sensory input reaction in which was reflected in their learning in the classroom.

Both interventions, Pivotal Response Treatment (PRT) and therapeutic horseback riding treatment are lined up with the latest research regarding the importance of natural environment in eliciting children with autism social communication (Koegel et al., 2006). Alshirawi \& Alzayer (2018) conducted a quantitative study in which they hypothesized that integrating PRT and therapeutic horseback riding interventions would yield a significant positive outcome in the core autism symptoms that are social functioning, communication, and restricted behaviors. Eight children with autism participated in the experimental group, which received the intervention of Pivotal Response Treatment (PRT) during the horseback riding activity in a horse stable, for eight consecutive weeks, and four times a week for one hour. The children participants attended the intervention activity with their parents. The parents were given brief training on how to enhance their children social skills using the principles of PRT. Social interaction and guidelines were facilitated and provided to the parents and their children by the researcher.

\section{Method}

A qualitative research method was conducted in this study. Specifically, open-ended questions were implemented to the sample which consisted of the parents of 5 autistic children that participated in a previous study which included the intervention of Pivotal Response Treatment (PRT) with horseback riding activity to the autistic children for eight consecutive weeks, four times a week for one hour (Creswell, 2012). The primary purpose of this study was to identify parents' perspectives concerning the impacts of the integrated invention of pivotal response intervention delivered within the natural environmental activity of horseback riding in the life of their children with autism at home, and across natural inclusive settings. 


\section{Participants}

The participants of this study are 5 female parents of autistic children that were subject to a previous study which included the introduction of Pivotal Response Treatment (PRT) with horseback riding activity to the autistic children for eight consecutive weeks, that study was compromised of 16 autistic children. Of these, 8 were introduced to the horse riding program, and of those 8,5 autistic children aged 5-8 that showed significant improvement in social communication and sensory processing. Due to this significant improvement, their parents were qualitatively interviewed to assess the following points:

\section{Parents Perspective Regarding delivering PRT Intervention to their Children}

\section{Significant Change in the Child's Communication Across Different Natural Settings}

\section{Significant Change in the Child's Sensory Integration}

\section{Data collection and analysis}

After the participants responded to the contact by telephone, the researchers scheduled appointments to meet with them all as a group in the Autism center in Bahrain. The focus group included five parents of children with autism who were part of the integrated invention of pivotal response intervention delivered within the natural environmental activity of horseback riding in a horse stable, for eight consecutive weeks, four times a week for one hour. The interview took approximately two hours and was conducted in Arabic, which was the native language of these participants. Moreover, the participants were asked five semi-structured, open-ended interview questions, which were also provided to them in writing. The fundamental demographic, descriptive, and the interview questions addressed the Perspectives regarding the PRT intervention, the benefit of attending the training with their children in the horse stable, and perceptions in implementing this integrated intervention as a natural part of routines. Other questions addressed include the significant change in the child's communication, considerable variation in the child's sensory integration, and the impact of this integrated intervention on the children's behavior at home and across other natural settings. The researchers recorded the interviews digitally, and field notes were noted down and then were translated and transcribed into English by the researchers. The data was then qualitatively narratively analyzed to identify common themes.

\section{Findings}

As described in the previous section, the parents of the focus group reported their experience of how their children benefited from this integrated intervention in which also parents were considered as an essential agent of intervention delivery.

Key influence elements that were discussed across the emerged themes included (a) eye contact and joint attention, (b) peers and adults' interaction, (c) verbal and non-verbal communication, (d) behavioral issues, (e) eating and sleeping patterns, and (f) self-stimulatory behaviors. 


\section{Parents' Perspective Regarding delivering PRT Intervention to their Children}

Parents' participants reported that PRT integrated within horseback riding was a flexible and an enjoyable intervention. The parents reported that they had always been struggling with how to identify means to do interactive leisure activity with their children with autism. The parents also noted that the challenge of identifying an interactive leisure activity for their children was always a stressful moment when they would go out with them due to the behavioral and sensory issues, which they did not manage to control efficiently. They stated that PRT is a very valuable intervention in which it evokes language and skills, and at the same time, it is easy to follow and learn. Parents also stated that they enjoyed the whole experience because they were positively interacting with their children(e.g., riding the horse with them, feeding the horse with them, and touching different animals in the stable). Parents also agreed that PRT follows the child's lead. The children were all reinforced by the ride; as a result, they were very responsive to their parents when they asked them about something. One of the mothers stated, "I enjoyed when I stopped the horse, and asked my son about the color of the horse or the color of the tree, and my son said the correct color, then I reinforced him by continuing the horse ride."Concerning eye contact and joint attention, all the mothers reported that they learned how to prompt their children's joint attention by stopping the horse movement, saying "look who is flying in the sky," and the children would look. In this instance, the mother reinforced the child by continuing with the horse ride. All the parents' participants reported that learning about PRT intervention made them less stressed of how to spend quality time with their children. They felt that they were doing something to help their children and learned how to enhance their children's skills and how to teach them new skills.

\section{Significant Change in the Child's Communication Across Different Natural Settings}

At the beginning of the study, parents were provided with the theatrical overview about PRT and its benefit in children communication. Therefore, parents were instructed to work on children's joint attention and eye contact throughout the ride. Parents stated that they were able to extend this skill across all natural settings in their daily routines. Besides, parents reported that they noticed an improvement in their children's turn taking and most importantly, they noticed an improvement in their toddler's waiting time. All the mothers stated that "my son became calmer when went to the playground, he became more able to wait patiently for his turn for the slide behind the peers, unlike before, he was pushing others, screaming, and crying to get a turn." Mothers also reported that their children became more interactive with them. They became more able to initiate and reciprocate greetings as this was also targeted during the intervention. In terms of peers' interaction, the mothers stated the children we better accepting parallel play or playing shortly with their typical peers. For children who were non-verbal, the mothers stated that they noticed changes in motor/verbal imitation. They were able to work on these skills at home, as they were exactly doing during the intervention time in the horse stable. The mother stated "I asked my son to clap by saying "do this!" he was able to imitate the actions. This skill was also generalized at home, and when his father asked him to imitate an action such as touch your head, the child was able to respond by imitating what was requested". These observations were also consistent with the literature regarding the effectiveness of task variation on increasing responsively to multiple 
cues and variation (Dunlap \& Koegel, 1980). PRT is a multicomponent intervention that targets pivotal areas such as motivation, social initiation, and self-regulation to manage and monitor behaviors (L. K. Koegel et al., 1998). PRT also has a collateral effect in different areas of concern related to autism such as fostering children's communication and language, developing social-emotional abilities, increasing cognition, and improving behavior (Levy et al., 2006). In addition, the observed increase in social communication might be attributed to several factors. First, horseback riding activity that was very stimulating activity in terms of being associated with physical attendance, texture, and the movement of the horse in which also saturated the children's sensory needs so that the children are more calmer and focus on learning new skills (Bass, Duchowny, \&Llabre, 2009).

\section{Significant Change in the Child's Sensory Integration}

Sensory processing involves sensory adaptation that allows individuals to respond to sensory stimulation purposefully. Adaptive response is one of the requisite skills needed in the learning process and social interaction of everyday living for children with ASD (Tomchek, Little, \& Dunn, 2015). With regard to sensory integration, parents stated that children improved incritical areas such as sensory integration and directed attention. Children also demonstrated improved social motivation and sensory sensitivity. Parents noted that children showed improvement with regard the reaction when being touched (e.g., aggression) and became more willing to take risks (e.g., refuse to ride the horse at the beginning). The children became less anxious in over stimulating environments such as malls, schools, or playgrounds. For children who had tactile defensiveness, the mothers stated that that "we noticed that our children became more tolerant of touching different substances such as sand, mud, or horse food."Moreover, as reported by all the parent's participants, the children became calmer and less hyperactive, this might be deducted from the fact that exposure to the horses was simply stimulating. The multisensory nature of the therapeutic horseback riding indicated that this experience might have been a very stimulating event that was directly associated either with the physical presence or with the natural movement of the horse that saturated the need for sensory input that most children with autism required. The act of riding the horse may have been perceived as a rewarding stimulus that accounted for higher levels of motivation and social engagement (Ashburner et al., 2008).Regarding children with sensory seeking conditions, they had a prolonged visual inspection of toys. They also exhibited repetitive behavior when handling objects. The deficiency in sensory processing hinders the ability of individuals to give meaning of their experience by analyzing all the information and selecting what to focus on and what to ignore (i.e., listen to the teacher and ignore the noise of other children). In addition, sensory processing deficiency can negatively affect children's behavior, which explains why some of these children exhibited hyperactivity, repetitive movements, and mothing behaviors (Miller et al., 2007).

\section{Discussion}

The present qualitative study was developed with the intent to determine the parents' perceptions of how the intervention affects the lives of their children at home and across different natural settings. Key influences included (a) eye contact and joint attention, (b) 
peers and adults' interaction, (c) verbal and non-verbal communication, (d) behavioral issues, (e) eating and sleeping patterns, and (f) self-stimulatory behaviors.

Family involvement has several advantages including but not limited to enhancing spontaneity, generalization, and maintenance of the intervention, increasing parent's self-efficacy, and ensuring the consistency of the intervention (Lovaas et al., 1973). These findings highlighted the importance of valuing family sociocultural environments and daily routines when planning effective interventions. Moreover, assessing family sociocultural environments helps parents in setting goals, planning instructions, and implementing strategies that provide them with a powerful lead that positively enhances the sustainability and generalizability of skills across settings. Research has shown that family involvement is a critical component of any effective behavioral intervention program for children with disabilities (Schopler \& Reichler, 1971). Pivotal Response Training is a comprehensive approach that requires parent involvement in the delivery process and considers them as essential intervention agents (Baker et al., 1998). Lovaas, Koegel, Simmons, and Long (1973) conducted a follow-up study on children with autism who received one year of intensive behavioral intervention. Researchers noted a positive intervention gain on students who received the intervention by their trained parents. Children were more likely to respond to their parents than they do with the clinicians; also, the intervention could be extended at home and community for generalization (Schopler et al., 1971).

Embedding the intervention within family activities and daily routines provided significant social communication and behavioral learning opportunities. It also enhanced positive interaction among family members. In addition, training parents on the intervention had a substantial effect on the parents because they gained a better understanding of the characteristics of autism and how to address its symptoms head on (Souto-Manning \& Swick, 2006).

Kashinath, Woods, \& Goldstein, 2006) conducted a study to examine the effects of facilitating the generalization of teaching strategies implemented by parents within daily routines at home. The study demonstrated that parents were able to implement the intervention strategies and generalize the teaching across different daily activities. The five children in the study demonstrated positive communication abilities across daily routines and activities. However, the researchers reported the need for further research on parent education that includes various individuals' age group and disabilities, and with diverse family characteristics.

From a developmental stance, meaningful parent involvement has a positive impact on the joint attention ability that is lacking with most children with autism. Siller and Sigman (2002) examined the effect of parent involvement during play interaction on the child's joint attention. The researchers found that when parents are involved with their child's focus of attention during natural play interaction, these children had better joint attention ability needed for effective social communication skills(Henderson \& Mapp, 2002; Jeynes, 2005). Parents tend to be more responsive to their child's communicative responses and attempts (Kravits, Kamps, Kemmerer, \& Potucek, 2002; Von Tetzchner, Brekke, Sjothun, \& 
Grindheim, 2005).

The current investigation complements and expands the research base focusing on the effect of parents' involvement on the communication outcomes of young children with autism. Due to noticeable changes in children social communication and due to the noticeable decrease in children's behaviors and sensory issues, all parent's participants requested support to continue this intervention in the horseback riding stable. In addition, the autism center all parents of children participants agreed to add this integrated intervention of Pivotal Response Treatment within horseback riding activity to their children program agenda.

However, Additional studies are needed to overcome the limitations of this study that included limited sample size. The primary limitation seen in horseback riding as an interactive leisure activity is that not all parents can afford this type of event. It should also be noted that the research included few sessions of horseback riding. Surely, with more than eight sessions it would have been possible to discover many more improvements and advances in these children since the more extended treatment would have worked much more in the areas most affected or more challenging to improve.

\section{References}

Adamson, L. B., McArthur, D., Markov, Y., Dunbar, B., \& Bakeman, R. (2001). Autism and joint attention: Young children's responses to maternal bids. Journal of Applied Developmentaul Psychology, 22(4), 439-453. https://doi.org/10.1016/S0193-3973(01)00089-2

Ashburner, J., Ziviani, J., \& Rodger, S. (2008). Sensory processing and classroom emotional, behavioral, and educational outcomes in children with autism spectrum disorder. The American Journal of Occupational Therapy: Official Publication of the American Occupational Therapy Association, 62(5), 564-573. https://doi.org/10.5014/ajot.62.5.564

Ausderau, K., Sideris, J., Furlong, M., Little, L. M., Bulluck, J., \& Baranek, G. T. (2014). National survey of sensory features in children with ASD: Factor structure of the sensory experience questionnaire (3.0). Journal of Autism and Developmental Disorders, 44(4), 915-925. https://doi.org/10.1007/s10803-013-1945-1

Baker, A. E. Z., Lane, A., Angley, M. T., \& Young, R. L. (2008). The relationship between sensory processing patterns and behavioural responsiveness in autistic disorder: A pilot study. Journal of Autism and Developmental Disorders, 38(5), 867-875. https://doi.org/10.1007/s10803-007-0459-0

Baker, M. J., Koegel, R. L., \& Koegel, L. K. (1998). Increasing the social behavior of young children with autism using their obsessive behaviors. Research and Practice for Persons with Severe Disabilities, 23(4), 300-308. https://doi.org/10.2511/rpsd.23.4.300

Baranek, G. T. (2002). Efficacy of sensory and motor interventions for children with autism. Journal of autism and developmental disorders, 32(5), 397-42Bass, M. M., Duchowny, C. A., \&Llabre, M. M. (2009). The effect of therapeutic horseback riding on social functioning in children with autism. Journal of autism and developmental disorders, 39(9), 1261-1267. 
Bruinsma, Y., Koegel, R. L., \& Koegel, L. K. (2004). Joint attention and children with autism: A review of the literature. Mental Retardation and Developmental Disabilities Research Reviews, 10(3), 169-175. https://doi.org/10.1002/mrdd.20036

Coolican, J., Smith, I. M., \& Bryson, S. E. (2010). Brief parent training in pivotal response treatment for preschoolers with autism. Journal of Child Psychology and Psychiatry, 51(12), 1321-1330. https://doi.org/10.1111/j.1469-7610.2010.02326.x

Dawson, G. (2008). Early behavioral intervention, brain plasticity, and the prevention of autism spectrum disorder. Developmental and Psychopathology: Special Issues. Integrating Biological Measures into the Design of Evaluation of Preventive Interventions, 20(3), 775-803. https://doi.org/10.1017/S0954579408000370

Dawson, G., \& Watling, R. (2000). Interventions to facilitate auditory, visual, and motor integration in autism: A review of the evidence. Journal of autism and developmental disorders, 30(5), 415-421. https://doi.org/10.1023/A:1005547422749

Fortunato, J. A., Sigafoos, J., \& Morsillo-Searls, L. M. (2007). A communication plan for autism and its applied behavior analysis treatment: A framing strategy. Child and Youth Care Forum, 36(2), 87-97. https://doi.org/10.1007/s10566-007-9034-2

Hilton, C. L., Harper, J. D., Kueker, R. H., Lang, A. R., Abbacchi, A. M., Todorov, A., \& LaVesser, P. D. (2010). Sensory responsiveness as a predictor of social severity in children with high functioning autism spectrum disorders. Journal of autism and developmental disorders, 40(8), 937-945. https://doi.org/10.1007/s10803-010-0944-8

Howlin, P. (2006). Autism spectrum disorders. Psychiatry, 5(9), 320-324. https://doi.org/10.1053/j.mppsy.2006.06.007

Kashinath, S., Woods, J., \& Goldstein, H. (2006). Enhancing generalized teaching strategy use in daily routines by parents of children with autism. Journal of Speech, Language and Hearing Research, 49(3), 466. https://doi.org/10.1044/1092-4388(2006/036)

Koegel, L. K., Camarata, S. M., Valdez-Menchaca, M., \& Koegel, R. L. (1998). Setting generalization of question-asking by children with autism. American Journal of Mental $\begin{array}{lll}\text { Retardation: } & \text { AJMR, } & 102(4),\end{array}$ https://doi.org/10.1352/0895-8017(1998)102<0346:SGOQBC>2.0.CO;2

Koegel, L. K., Camarata, S. M., Valdez-Menchaca, M., \& Koegel, R. L. (1998). Setting generalization of question-asking by children with autism. American Journal of Mental Retardation: $\quad$ AJMR, $102(4), \quad 346$. https://doi.org/10.1352/0895-8017(1998)102<0346:SGOQBC >2.0.CO;2

Koegel, R. L., \& Frea, W. D. (1993). Treatment of social behavior in autism through the modification of pivotal social behaviors. Journal of Applied Behavior Analysis, 26, 369-377. https://doi.org/10.1901/jaba.1993.26-369

Koegel, R. L., \& Koegel, L. K. (Eds.). (2006). Pivotal response treatments for autism: Communication, social, and academic development. Baltimore, MD: Paul Brookes. 
Koegel, R. L., Koegel, L. K., \& Surratt, A. (1992). Language intervention and disruptive behavior in preschool children with autism. Journal of Autism and Developmental Disorders, 22(2), 141-153. https://doi.org/10.1007/BF01058147

Koegel, R. L., O'Dell, M., \& Dunlap, G. (1988). Producing speech use in nonverbal autistic children by reinforcing attempts. Journal of Autism and Developmental Disorders, 18(4). https://doi.org/10.1007/BF02211871

Kravits, T. R., Kamps, D. M., Kemmerer, K., \& Potucek, J. (2002). Brief report: Increasing communication skills for an elementary-aged student with autism using the picture exchange communication system. Journal of Autism and Developmental Disorders, 32(3), 225-230. https://doi.org/10.1023/A:1015457931788

Levy, K. N., Clarkin, J. F., Yeomans, F. E., Scott, L. N., Wasserman, R. H., \& Kernberg, O. F. (2006). The mechanisms of change in the treatment of borderline personality disorder with transference focused psychotherapy. Journal of clinical psychology, 62(4), 481-501. https://doi.org/10.1002/jclp.20239

Lovaas, O. I. (1987). Behavioral treatment and normal educational and intellectual functioning in young autistic children. Journal of Consulting and Clinical Psychology, 55(1), 3-9. https://doi.org/10.1037/0022-006X.55.1.3

Lovaas, O. I., Koegel, R. L, Simmons, J. Q., \& Long, J. S. (1973). Some generalization and follow-up measures on autistic children in behavior therapy. Journal of Applied Behavior Analysis, 6(1), 131-166. https://doi.org/10.1901/jaba.1973.6-131

Lovaas, O. I., Koegel, R. L, Simmons, J. Q., \& Long, J. S. (1973). Some generalization and follow-up measures on autistic children in behavior therapy. Journal of Applied Behavior Analysis, 6(1), 131-166. https://doi.org/10.1901/jaba.1973.6-131

Lucyshyn, J. M., Albin, R. W., \& Nixon, C. D. (1997). Embedding comprehensive behavioral support in family ecology: An experimental, single case analysis. Journal of Consulting and Clinical Psychology, 65(2), 241. https://doi.org/10.1037/0022-006X.65.2.241

Lucyshyn, J. M., Albin, R. W., \& Nixon, C. D. (1997). Embedding comprehensive behavioral support in family ecology: An experimental, single case analysis. Journal of Consulting and Clinical Psychology, 65(2), 241. https://doi.org/10.1037/0022-006X.65.2.241

Martin, F., \& Farnum, J. (2002). Animal-assisted therapy for children with pervasive developmental disorders. Western journal of nursing research, 24(6), 657-670. https://doi.org/10.1177/019394502320555403

Miller, L. J., Anzalone, M. E., Lane, S. J., Cermak, S. A., \& Osten, E. T. (2007). Concept evolution in sensory integration: A proposed nosology for diagnosis. American Journal of Occupational Therapy, 61(2), 135-140. https://doi.org/10.5014/ajot.61.2.135

Mundy, P., Sigman, M., \& Kasari, C. (1990). A longitudinal study of joint attention and language development in autistic children. Journal of Autism and Developmental Disorders, $20,115-128$. 
National Research Council, Committee on Educational Interventions for Children with Autism. (2001). Educating children with autism. Washington, DC: National Academy Press.

Pierce, K., \& Schreibman, L. (1995). Increasing complex social behaviors in children with autism: Effects of peer-implemented pivotal response training. Journal of Applied Behavior A Jones, C. D., \& Schwartz, I. S. (2009). When asking questions is not enough: An observational study of social communication differences in high functioning

Prizant, B. M., \& Wetherby, A. M. (2008). Understanding the continuum of discrete-trial traditional behavioral to social-pragmatic developmental approaches in communication enhancement for young children with Autism/PDD. Seminars in Speech and Language, 19(4), 329-353. https://doi.org/10.1055/s-2008-1064053

Prothmann, A., \& Fine, A. H. (2011). Animal-assisted interventions in child psychiatry. Animals in our lives: Human-animal interaction in family, community and therapeutic settings, 143-162.

Schaaf, R. C., \& Lane, A. E. (2015;2014;). Toward a best-practice protocol for assessment of sensory features in ASD. Journal of Autism and Developmental Disorders, 45(5), 1380-1395. https://doi.org/10.1007/s10803-014-2299-z

Schopler, E., \& Reichler, R. J. (1971). Parents as cotherapists in the treatment of psychotic children. Journal of Autism \& Childhood Schizophrenia, 1(1), 87-102. https://doi.org/10.1007/BF01537746

Siller, M., \& Sigman, M. (2002). The behaviors of parents of children with autism predict the subsequent development of their children's communication. Journal of Autism and Developmental Disorders, 32(2), 77-89. https://doi.org/10.1023/A:1014884404276

Souto-Manning, M., \& Swick, K. J. (2006). Teachers' beliefs about parent and family involvement: Rethinking our family involvement paradigm. Early Childhood Education Journal, 34(2), 187-193. https://doi.org/10.1007/s10643-006-0063-5

Tomchek, S. D., Little, L. M., \& Dunn, W. (2015). Sensory pattern contributions to developmental performance in children with autism spectrum disorder. American Journal of Occupational Therapy, 69(5), 6905185040p1-6905185040p10. https://doi.org/10.5014/ajot.2015.018044

von Tetzchner, S., Brekke, K. M., Sjøthun, B., \& Grindheim, E. (2005). Constructing preschool communities of learners that afford alternative language development. Augmentative and alternative communication, 21(2), 82-100. https://doi.org/10.1080/07434610500103541

Ward, S. C., Whalon, K., Rusnak, K., Wendell, K., \& Paschall, N. (2013). The association between therapeutic horseback riding and the social communication and sensory reactions of children with autism. Journal of autism and developmental disorders, 43(9), 2190-219. https://doi.org/10.1007/s10803-013-1773-3 


\section{Macrothink}

Journal of Studies in Education ISSN 2162-6952

Yoder, P., \& Stone, W. L. (2006). Randomized comparison of two communication interventions for preschoolers with autism spectrum disorders. Journal of consulting and clinical psychology, 74(3), 4. https://doi.org/10.1037/0022-006X.74.3.426 